\title{
Genomic stability in Arabidopsis thaliana transgenic plants obtained by floral dip
}

Received: 9 April 2004 / Accepted: 8 July 2004 / Published online: 5 August 2004

C) Springer-Verlag 2004

\begin{abstract}
The occurrence of DNA modification is an undesired phenomenon accompanying plant cell transformation. The event has been correlated with the stress imposed by the presently utilised transformation procedures, all depending on plant differentiation from in vitro cell culture, but other causes have not been excluded. In this work, transgenic Arabidopsis thaliana plants have been produced by an approach that does not require cell dedifferentiation, being based on in planta Agrobacteriummediated gene transfer by flower infiltration, which is followed by recovery and selection of transgenic progeny. Genomic DNA changes in transgenic and control plants have been investigated by AFLP and RAMP analysis. Results show no statistically relevant genomic modifications in transgenic plants, as compared with control untreated plants. Variations were observed in callusderived $A$. thaliana plants, thus supporting the conclusion that somaclonal variation is essentially correlated with the stress imposed by the in vitro cell culture, rather than with the integration of a foreign gene.
\end{abstract}

Communicated by F. Salamini

M. Labra $(\bowtie)$

Department of Environmental Science, University of MilanoBicocca,

Piazza della Scienza 1,

20126 Milan, Italy

e-mail: massimo.labra@unimib.it

Fax: +39-2-63482996

C. Vannini $\cdot$ M. Bracale $\cdot$ M. Balsemin

DBSF, University of Insubria,

via J.H. Dunant 3 ,

21100 Varese, Italy

F. Grassi · F. Sala

Botanical Garden, Department of Biology, University of Milan,

via Celoria 26,

20133 Milan, Italy

B. Basso · F. Sala

IBF, CNR, Department of Biology, University of Milan,

via Celoria 26,

20133 Milan, Italy

\section{Introduction}

Larkin and Scowcroft (1981) defined somaclonal variation as the sum of genetic and epigenetic changes that occur in the clonal progeny of a single parental plant clone and that are stably inherited by the clonal and sexual progeny. The occurrence of somaclonal variants has been documented at the molecular as well as at the morphological and functional level (Karp 1991; Cervera et al. 2000; Etienne and Bertrand 2003).

Somaclonal variation has been shown to be triggered in plants that have undergone stress of different nature, such as adverse environmental conditions and cell culture in the dedifferentiated state (in vitro culture) (Cullis and Kolodynska 1975; Cullis and Cleary 1986; Cullis 1990; Phillips et al. 1994). In general terms, DNA changes are believed to be the consequence of a disturbance of the normal cellular control. However, very little is known about the mechanisms that trigger such changes. Information on this phenomenon is highly desirable, since there is a need to suppress it in some cases (e.g. in transgenic plant production) or to exploit it in others (e.g. in plant breeding). In absence of tools for intervention on the primary cellular events of somaclonal variation, research has focused on the search for tools to verify its occurrence and on the description of conditions that trigger it.

Somaclonal variation occurs in transgenic plants. It has been observed in different transgenic plant populations, such as rice (Bao et al. 1993; Arenciba et al. 1998; Labra et al. 2001), barley (Bregitzer et al. 1998), tomato (Soniya et al. 2001), potato (Dale and McPartlan 1992; Beaujean et al. 1998), poplar (Wang et al. 1996), cotton (Sachs et al. 1998), tobacco (Touraev et al. 1997) and sugarcane (Arencibia et al. 1999). The analysis of three successive generations of self pollinated transgenic rice plants has shown that genomic changes are carried to the progeny, where they segregate upon sexual reproduction (Bao et al. 1993). Variation has been correlated with the stress imposed by the presently utilised transformation procedure, depending on plant differentiation from in vitro cell culture. The extent of somaclonal variation, calculated as 
frequency of DNA changes, has been correlated with the extent and severity of the in vitro stress (Sala et al. 2000; Labra et al. 2001).

An open question remains: can we get rid of somaclonal variation in transgenic plants by avoiding the in vitro culture steps?

In the present paper, this problem has been investigated by verifying the occurrence of genomic changes in transgenic Arabidopsis thaliana plants produced with the 'floral-dip' approach. This Agrobacterium-mediated approach, based on in planta flower infiltration, is unique in the fact that it does not require in vitro cell culture (Bechtold et al. 1993). This leads to direct uptake of the bacterial plasmid DNA by the egg cells (or their progenitor cells) and to integration of the foreign DNA into the nuclear DNA of recovered transgenic seeds (Clough and Bent 1998; Ye et al. 1999; Bechtold et al. 2000; Desfeux et al. 2000).

Genomic DNA changes have been investigated by AFLP and RAMP analysis. AFLP and RAMP markers allow simultaneous analysis of a large number of loci in different genomic sites and provide stable and reproducible patterns of band amplification.

Results show no statistically relevant genomic changes in transgenic plants obtained by this approach, as compared with control untreated plants. Genomic changes were observed in callus-derived $A$. thaliana plants, thus suggesting that somaclonal variation is correlated with stress imposed by the in vitro cell culture and not by integration of a foreign gene.

\section{Materials and methods}

Plant material and DNA extraction

A. thaliana (cv. Wassilewskija) transgenic plants were produced through the floral-dip method (Clough and Bent 1998). Agrobaceterium tumefaciens strain GV3101 (pMP90) was transformed with the plasmid pBINmgfp5-ER carrying the GFP and nptII genes coding for the green fluorescent protein and for kanamycin resistance, respectively. Both genes were under the control of the CaMV 35S promoter (http://www.plantsci.cam.ac.uk/Haseloff/docs/LabPDFs/mgfp5ER).

Ten $A$. thaliana plants ( $\mathrm{T}_{0}$ population) were transformed by the floral-dip technique. Seeds obtained from these plants were divided into two groups. The first group was germinated in Magenta boxes containing MS medium (Murashige and Skoog 1962) supplemented with $100 \mu \mathrm{g} \mathrm{ml}^{-1}$ kanamycin. The second was germinated in the same conditions, except that kanamycin was omitted and plantlet selection was performed on the bases of GFP fluorescence, as verified by visual inspection with a Leica DC100 FLUO Stereomicroscope (Leica Microsystems, Milan, Italy).

Eight plants ( $T_{1}$ generation) selected for kanamycinresistance and eight plants selected for GFP fluorescence were randomly recovered within each of the ten offspring.
Transgene presence was verified by PCR amplification in the presence of appropriate DNA primers (data not shown).

Plants derived from $A$. thaliana callus cultures were produced with the following procedure:

1. Seeds were germinated on MS medium with $20 \mathrm{~g} \mathrm{l}^{-1}$ sucrose at $23^{\circ} \mathrm{C}, 100 \mu \mathrm{M} \mathrm{m}^{-2} \mathrm{~s}^{-1}$ of white light and $16 / 8 \mathrm{~h}$ photoperiod.

2. Root segments (5-7 mm long) were excised from 13day-old seedlings and incubated for 7 days on callusinducing-medium (CIM) containing MS medium, 3\% sucrose, $0.5 \mathrm{mg} \mathrm{l}^{-1} 2,4 \mathrm{D}$ and $0.3 \mathrm{mg} \mathrm{l}^{-1}$ kinetine.

3. The root fragments were then transferred to shootinducing-medium (SIM) containing Gamborg's B5 medium, $2 \%$ glucose, $0.15 \mathrm{mg} \mathrm{l}^{-1}$ IAA and $5 \mathrm{mg} \mathrm{l}^{-1} \mathrm{N6}$-(2-isopentenyl)adenine.

Plant differentiation was from dedifferentiated cells. A total of 18 regenerated plants, each one derived from a different callus, was selected for DNA analysis.

The transgenic and control plant populations $(\mathrm{a}-\mathrm{e})$ to be analysed were composed as follows:

1. Population a: 80 transgenic individuals $\left(\mathrm{T}_{1}\right.$ plants $)$ selected for kanamycin resistance.

2. Population b: 80 transgenic individuals $\left(\mathrm{T}_{1}\right.$ plants) selected for GFP fluorescences.

3. Population c: 80 non-transgenic individuals $\left(T_{1}\right.$ plants), selected within the $\mathrm{b}$ population among those that did not show fluorescence and transgene presence.

4. Population d: 25 non-transgenic individuals obtained from the seeds of five independent control (nontransgenic) plants.

5. Population e: 18 plants regenerated from callus culture.

DNA was extracted from young basal leaves, using the Plant Tissue Kit (Qiagen, Calif., USA), following the manufacturer's instructions.

\section{AFLP analysis}

AFLP analysis was performed as described by Labra et al. (2001), except that genomic DNA (200 ng) was digested with EcoRI $(0.5 \mathrm{U})$ and $M s e \mathrm{I}(0.5 \mathrm{U})$ for $3 \mathrm{~h}$ before ligation to EcoRI and MseI adapters (5 pmol and 50 pmol, respectively). Pre-amplification was performed using the primer pair M01 and E01, and selective amplification using one of the following ten primer pairs: E31-M36, E31-M40, E33-M37, E33-M40 E34-M40, E37-M36, E37M38, E39-M32, E39-M33, or E39-M40. Primer sequences are shown in Table 1. A total of $1.5 \mu \mathrm{l}$ of the PCRamplified mixture was added to an equal volume of loading buffer $\left(80 \%\right.$ formamide, $1 \mathrm{mg} \mathrm{ml}^{-1}$ xylene cyanol FF, $1 \mathrm{mg} \mathrm{ml}^{-1}$ bromophenol blue, $10 \mathrm{mM}$ EDTA, $\mathrm{pH} 8.0$ ), denatured for $5 \mathrm{~min}$ at $92^{\circ} \mathrm{C}$, loaded onto a $5 \%$ denaturing polyacrylamide gel and electrophoresed in TBE electrophoresis buffer for $3 \mathrm{~h}$ at $80 \mathrm{~W}$. The gel was finally fixed 
in $10 \%$ acetic acid and exposed to an X-ray film for $24 \mathrm{~h}$. Results were confirmed by duplicate AFLP analysis. Polymorphic bands were scored by visual inspection of the resulting autoradiograms.

\section{RAMP analysis}

RAMP analysis was performed by amplifying genomic DNA (10 ng), essentially as described by Wu et al. (1994). The K7 and K5 microsatellite primers (Table 1) were endlabelled with $\gamma\left[{ }^{33} \mathrm{P}\right]$-ATP (Amersham, Italy). The reaction mixture $(10 \mu \mathrm{l})$ contained $0.1 \mu \mathrm{M}$ of one of the two labelled primers, $0.2 \mathrm{mM}$ RAPD primers (J8 and OPH 19), $200 \mu \mathrm{M}$ of each dNTP, $0.5 \mathrm{U}$ of Dynazyme polymerase (Finzyme, Finland) and Dynazyme buffer as specified by the supplier. PCR amplification was performed with a programmable thermal cycler (Techne) with the following protocol: $95^{\circ} \mathrm{C}$ for $3 \mathrm{~min}$ (one cycle), $95^{\circ} \mathrm{C}$ for $20 \mathrm{~s}, 32^{\circ} \mathrm{C}$ for $1 \mathrm{~min}, 72^{\circ} \mathrm{C}$ for $1 \mathrm{~min}(35 \mathrm{cycles})$, and $72^{\circ} \mathrm{C}$ for $7 \mathrm{~min}$ (one cycle).

\section{Statistical analysis}

Each AFLP and RAMP band was scored as a binary character for absence (0) or presence (1), and genomic variability within each analysed plant population was calculated as described in Table 2. In the case of RAMP, no polymorphism was detected; thus, results were sufficiently simple as to be directly interpreted. Indexes to define genomic variability among plants, based on the AFLP analysis, are described in Table 2. The UPGMA dendrogram showing genomic distance was computed, in accordance with numeric taxonomy principles, with the

Table 1 DNA primer sequences used for the AFLP and RAMP analysis

\begin{tabular}{ll}
\hline Name & DNA sequence \\
\hline E01 & 5'-GAC TGC GTA CCA ATT CA-3' \\
M01 & 5'-GAT GAG TCC TGA GTA AA-3' \\
E31 & 5'-GAC TGC GTA CCA ATT CAA A-3' \\
E33 & 5'-GAC TGC GTA CCA ATT CAA G-3' \\
E34 & 5'-GAC TGC GTA CCA ATT CAA T-3' \\
E37 & 5'-GAC TGC GTA CCA ATT CAC G -3' \\
E39 & 5'-GAC TGC GTA CCA ATT CAG A-3' \\
M32 & 5'-GAT GAG TCC TGA GTA AAA C-3' \\
M33 & 5'-GAT GAG TCC TGA GTA AAA G-3' \\
M36 & 5'-GAT GAG TCC TGA GTA AAC C-3' \\
M37 & 5'-GAT GAG TCC TGA GTA AAC G-3' \\
M38 & 5'-GAT GAG TCC TGA GTA AAC T-3' \\
M40 & 5'-GAT GAG TCC TGA GTA AAG C-3' \\
K5 & 5'-CCA GGT GTG TGT GTG T-3' \\
K7 & 5'-CAA CTC TCT CTC TCT-3' \\
J8 & 5'-CATACCGTCC-3' \\
OPH19 & 5'-CTGACCAGCC-3' \\
\hline
\end{tabular}

simple matching (SM) coefficient (Sneath and Sokal 1973) by using the NTSYSpc, version 2.1, statistical programme.

\section{Results}

A. thaliana $\mathrm{T}_{0}$ plantlets were transformed with an $A$. tumefaciens strain carrying the nptII and the GFP genes by using the floral-dip approach. Seeds $\left(T_{1}\right.$ generation) were germinated and transgenic plants were selected for kanamycin resistance or GFP fluorescence emission (populations a and b, respectively). Controls were: population $\mathrm{c}$ (non-transgenic individuals selected within the $\mathrm{b}$ population), population d (individuals obtained from the seeds of non-transgenic plants) and population e (plants regenerated from callus culture).

DNA was purified from each individual, and genomic changes were investigated by AFLP and RAMP analysis. For AFLP was analysis, ten different DNA primer pairs were used as specified in "Materials and methods." Altogether, the analysis revealed a total of 524 DNA bands, $31(6 \%)$ of which were polymorphic.

Descriptive statistics of AFLP marker polymorphism in the analysed plant populations are given in Table 2. They shows that 77 and 75 transgenic plants within the 80 individuals of the $\mathrm{a}$ and $\mathrm{b}$ transgenic populations, respectively, did not show any DNA polymorphism. The remaining three and five plants in the two populations showed three and seven polymorphic bands, respectively.

An analogous polymorphic band frequency was found in the control populations, (c and d) as shown in Table 2. Thus, altogether the results show a comparable level of polymorphism in the transgenic plants ( $a$ and $b$ ) and in the non-transgenic ones (c and d).

The results reported above were substantially different from those obtained in the analysis of the e population, where all plants obtained from callus culture were found to carry DNA modifications. The DNA of the 18 analysed plants showed a total of 31 polymorphic bands. Their numbers ranged from one to ten per individual plant. Polymorphic DNA bands in the different regenerated plants were unique: only seven of them were present in more than one plant.

Values calculated from the experimental data for the percentage of polymorphism and polymorphic information content (PIC) indexes agreed with the conclusion that the e population is characterised by a considerably higher level of DNA polymorphism.

Values estimated for all other considered indexes agreed with the same conclusion (Table 2). In fact, when gene diversity (GD) among all analysed plants was computed, the highest value was detected in the e population, as compared with other analysed samples. Genomic variability for each population was also evaluated by applying the $\mathrm{Sh}, \mathrm{Na}$ and $\mathrm{Ne}$ indexes, all of them assessing allele richness. Data of Table 2 show the highest $\mathrm{Sh}, \mathrm{Na}$ and $\mathrm{Ne}$ values in the case of the e population.

A dendrogram, based on the data produced by AFLP analysis, was constructed. This shows genomic similarity 
Table 2 Descriptive statistics of AFLP markers, as estimated within the analysed plant populations

\begin{tabular}{|c|c|c|c|c|c|c|}
\hline \multirow[t]{2}{*}{ Indexes (abbreviations) } & \multirow[t]{2}{*}{ Equation } & \multicolumn{5}{|c|}{ Plant population $^{\mathrm{a}}$} \\
\hline & & a & $\mathrm{b}$ & $\mathrm{c}$ & d & e \\
\hline Number of polymorphic bands (np) & $\mathrm{np}$ & 3 & 7 & 2 & 3 & 31 \\
\hline $\begin{array}{l}\text { Percentage of polymorphism (np\%) in the analysed group } \\
\text { of plants }\end{array}$ & $\mathrm{np} \%=\mathrm{np} /$ total bands & 0.6 & 1.39 & 0.4 & 0.6 & 6.16 \\
\hline Number of individuals showing polymorphic bands $(U)$ & $U$ & 3 & 5 & 2 & 3 & 18 \\
\hline $\begin{array}{l}\text { Distribution of polymorphic bands }(D) . U \text { is the number of } \\
\text { individuals showing polymorphic bands; } T \text { is the total } \\
\text { number of individuals in the group }\end{array}$ & $D=U /$ total samples & 0.047 & 0.078 & 0.031 & 0.12 & 1 \\
\hline $\begin{array}{l}\text { Polymorphic information content (PIC). It is an arbitrary } \\
\text { index determined over all loci where } p_{1} \text { and } p_{0} \text { (presence or } \\
\text { absence) represent bands frequency }\end{array}$ & $\begin{array}{l}\mathrm{PIC}=\left[1-\sum\left(p_{1}^{2}+p_{0}^{2}\right)\right] \times \\
1000\end{array}$ & 0.751 & 0.4651 & 0.1167 & 0.4372 & 16,843 \\
\hline $\begin{array}{l}\text { Gene diversity (GD). It is determined over all loci where pi } \\
\text { is the frequency, in each group, of the } i \text { allele at each locus; } \\
\text { and } n \text { is the number of individuals in each group of } \\
\text { samples (Nei 1987) }\end{array}$ & $\mathrm{GD}=n(n-1)\left(1-\sum p i^{2}\right)$ & 0.0013 & 0.0033 & 0.0009 & 0.0019 & 0.0278 \\
\hline Shannon index (Sh) (Shannon 1949) & $\mathrm{Sh}=-\sum p_{i} \log _{2} p_{i}$ & 0.0022 & 0.0056 & 0.0015 & 0.003 & 0.0396 \\
\hline Observed number of alleles $(\mathrm{Na})$ & $\mathrm{Na}$ & 1.006 & 1.0139 & 1.004 & 1.006 & 1.0616 \\
\hline Effective number of alleles (Ne) (Kimura and Crow 1964) & $\mathrm{Ne}=1 /\left(1-\sum p_{i}^{2}\right)$ & 1.0017 & 1.0044 & 1.0011 & 1.0028 & 1.0514 \\
\hline
\end{tabular}

${ }^{a}$ Plant populations were as follows: $a$ transgenic individuals selected for kanamycin resistance; $b$ transgenic individuals selected for GFP fluorescences; $c$ non transgenic individuals, selected within the b population among those that did not show fluorescence and transgene presence, $d$ non transgenic individuals obtained from the seeds of independent non transgenic plants; and $e$ plants regenerated from callus culture

among all analysed transgenic and control plants (Fig. 1). The SM coefficient among all analysed samples varied from 1.0 (full genomic similarity) to 0.98 , showing low genomic variability among the analysed plants. The dendrogram demonstrates that the a, b, c and d populations, which had not undergone in vitro culture, are characterised by very high genomic similarity, regardless of the integration of the foreign gene. This is at variance

Fig. 1a-e Dendrogram based on the simple matching coefficient (SM coefficient), showing genomic similarity among transgenic plants (populations a and b), control plants (populations $\mathrm{c}$ and d) and plants regenerated from callus (population e), as determined from data produced by AFLP analysis of genomic DNA. a-e Refer to the plant populations listed in Material and methods. a-d Group of isomorphic individuals, originating from different populations. In all the other cases, polymorphic individuals within a population are identified by the population letter followed by an individual number. In the case of the e population, all individuals are polymorphic

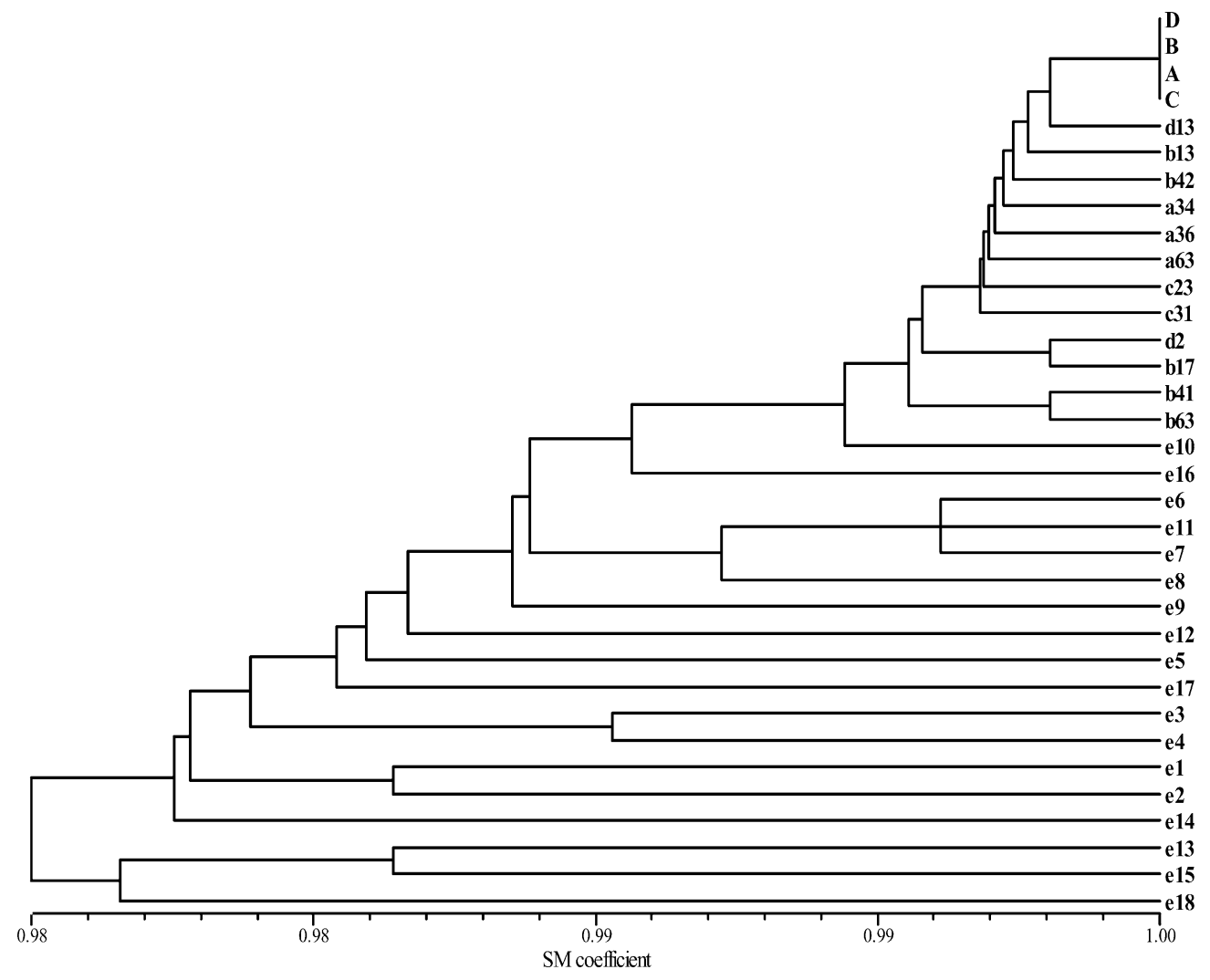


from plants of the e population (regenerated from in vitro culture), all of which plot in different positions. In agreement with these data, the GD value for the e population was significantly higher than that calculated for all other populations. This was particularly true for plants e13, e15, e18, e1, e 2 and e14 of the dendrogram.

The genome of the five populations was also analysed with the RAMP approach to specifically verify DNA polymorphism in genomic repeated sequences. Four different RAMP primer combinations (K5-J8, K7-J8, K5-OPA19 and K7-OPA19) were used. The number of amplified bands ranged from 26 to 41 in each case. No polymorphic bands were detected.

\section{Discussion}

It has been largely demonstrated that gene transfer into plants is associated with genomic modifications, and that these are inherited by the sexual and the clonal progeny (Sala et al. 2000). It has also been revealed that the extent of this variability is correlated with the transformation procedure and with the plant species. For instance, in the case of transgenic poplar produced via $A$. tumefaciens infection, the DNA of the totality of recovered transgenic plants was dissimilar from each other (Wang et al. 1996; Sala et al. 2000). Consistent genetic variability was also observed in the case of transgenic rice, when produced by protoplast transformation (Bao et al. 1993), particle bombardment, electroporation (Arencibia et al. 1998) and A. tumefaciens infection (Labra et al. 2001), respectively.

In all recorded cases, transformation was via a procedure that included plant cell dedifferentiation and differentiation. Now we give evidence that $A$. thaliana transgenic plants, obtained trough the floral-dip approach, are largely exempt from detectable genomic changes. In our analysis, the estimated PIC values were 0.75 and 0.46 (in the case of populations $a$ and $b$, respectively). Furthermore, the few detected polymorphic bands occurred at a frequency that was equivalent to that detected in control populations that had not undergone transformation. Thus, the background variability detected in all populations was most likely due to pre-existing genomic variability.

It has been proposed that genomic variability in transgenic plants may result from (1) tissue cultureinduced mutagenesis (Dolezel and Novak 1984; Sebastiani et al. 1994); (2) pre-existing genomic variability in the original plant population, as documented in crosspollinating (Palilov et al. 1981; Pooran and Singh 2003; Pradeep and sumalini 2003), self-pollinating (Miyashita et al. 1999; Bered et al. 2002) and cloned plants (Sala et al. 2000); and (3) insertion mutagenesis, whereby the foreign gene may disrupt the gene it is inserted into or close to (Koncz et al. 1992; Jong-Seong et al. 2000).

Transgenic A. thaliana produced through floral dip is characterised by the novelty that it does not require in vitro cell culture and plant differentiation (Desfeux et al. 2000).
Thus, this was an ideal tool to discriminate among the three proposed causes of somaclonal variation.

Our results, obtained by AFLP and RAMP analysis of non-transgenic and transgenic $A$. thaliana plants, show that the original population is already characterised by a low but detectable level of genomic variability. At the same time they exclude a relevant role of gene integration in somaclonal variation and point to the in vitro cell culture as the major factor inducing DNA changes. In fact, plants regenerated from callus culture showed random and frequent genomic changes. This agrees with data obtained when $A$. thaliana plants, derived from in vitro culture, were analysed by AFLP (Polanco and Ruiz 2002), or by verifying embryo lethality (up to $12.4 \%$ ), or chlorophyll mutations (up to 3.1\%) (Gaj and Maluszynski 1987).

The AFLP and RAMP markers are good tools to investigate the occurrence and frequency of genomic polymorphism in plants (Sala et al. 2000; Labra et al. 2001). The limitation is that these tools essentially analyse random or repetitive genome sequences and do not give direct information on the DNA region where exogenous genes are integrated. Thus, our results exclude events of genomic modification caused by gene integration but cannot give information on the occurrence of mutation of DNA sequences nearby the inserted T-DNA region.

The mechanism of Agrobacterium-mediated gene transfer and integration in plants have been extensively studied (Gelvin 2000; Zupan et al. 2000). However, the distribution pattern of T-DNA integration in plants and its correlation with the integration mechanisms and genomic rearrangement are still not explicit. Studies suggest that TDNA integration is a random process (Thomas et al. 1994; Barakat et al. 2000), but recent studies in A. thaliana have shown that transgene insertions preferentially occur in the $3^{\prime}$ and $5^{\prime}$ regulatory regions of genes and in introns rather than in exons (Brunaud et al. 2002; Szabados et al. 2002). This raises the possibility that the transgene may induce a mutation in the locus of its insertion. Màrton et al. (1994) reported the isolation of a nitrate-deficiency mutation in Nicotiana plumbaginifolia and showed that the low but consistent mutation frequency in the residential genes was increased two- to sixfold when protoplasts were transformed by A. tumefaciens with a non-homologous T-DNA. Therefore, they propose that the T-DNA can cause chromosomal mutation without being integrated at that position. Also, the limited co-segregation of mutation and T-DNA insert that was observed in T-DNA tagging experiments could be a result of this phenomenon (Koncz et al. 1992; Castle et al. 1993).

The RAMP analysis gave no evidence of a DNA polymorphism in the same $A$. thaliana plants, whereas AFLP did. The RAMP primers used in the analysis were those previously used in A. thaliana by Wu et al. (1994). RAMP analysis had shown polymorphism in transgenic sugarcane produced by cell electroporation (Arencibia et al. 1999) and in transgenic rice produced via particle bombardment and cell electroporation (Arencibia et al. 1998). In both cases plants were differentiated from in vitro culture. Wu et al. (1994) found few polymorphic 
RAMP bands when comparing 11 Arabidopsis ecotypes. In the present paper, we find no microsatellite polymorphism among transgenic Arabidopsis plants, as well as in plants regenerated from callus. Based on these results, we suggest that genomic polymorphisms in A. thaliana plants obtained from callus may occur predominantly, if not exclusively, in non-repetitive sequences.

In conclusion, our results add further evidence to the fact that different transformation techniques impose different levels of stress and consequently, cause different extents of DNA changes. Thus, from a practical point of view, the choice of the transformation protocol is not irrelevant for genome stability. The floral-dip approach is here shown to avoid or to reduce DNA changes to undetectable levels. In recent years the floral-dip approach was applied to other Arabidopsis species, such as $A$. lasiocarpa (Tague 2001) and A. suecica (Lawrence and Pikaard 2003). Reports on its use in other species are at present limited to Medicago truncatula (Trieu et al. 2000) and Raphanus sativus L. longipinnatus Bailey (Curtis and Nam 2000). It is highly desirable that research is conducted to broaden its application to other plants of agronomic value. There is no reason to believe that the approach cannot be extended to other plants, including those of agronomic relevance. Clough and Bent (1998) suggest that the critical point is the availability of plants with numerous immature floral buds. After Agrobacterium treatment, conditions for floral-bud culture should be optimised case by case, as suggested by Clough and Bent (1998), Curtis and Nam (2000) and Tague (2001).

\section{References}

Arencibia A, Gentinetta E, Cuzzoni E, Castiglione S, Kohli A, Vain P, Leech M, Christou P, Sala F (1998) Molecular analysis of the genome of transgenic rice (Oryza sativa L.) plants produced via particle bombardment or intact cell electroporation. Mol Breed 4:99-109

Arencibia A, Carmona ER, Cornide MT, Castiglione S, O'relly J, Chinea A, Oramai P, Sala F (1999) Somaclonal variation in insect-resistance transgenic sugarcane (Saccharum hibrid) plants produced by cell electroporation. Transgenic Res 8:349-360

Bao PH, Castiglione S, Giordani CL, Wang W, Datta SK, Datta K, Potrykus I, Sala F (1993) State of the foreign gene and of the genome in transgenic rice (Oryza sativa L.). Cytotechnology 11:123-125

Barakat A, Gallois P, Raynal M, Mestre-Ortega D, Sallaud C, Guiderdoni E, Delseny M, Bernardi G (2000) The distribution of T-DNA in the genomes of transgenic Arabidopsis and rice. FEBS Lett 471:161-164

Beaujean A, Sangwan RS, Lecardonnel A, Sangwan-Norreel BS (1998) Agrobacterium-mediated transformation of three economically important potato cultivars using sliced internodal explants: an efficient protocol of transformation. J Exp Bot 49:1589-1595

Bechtold N, Ellis J, Pellettier G (1993) In planta Agrobacteriummediated gene transfer by infiltration of adult Arabidopsis thaliana plants. CR Acad Sci 316:1194-1199

Bechtold N, Jaudeau B, Jolivet S, Maba B, Vezon D, Voisin R, Pelletier G (2000) The maternal chromosome set is the target of the T-DNA in the in Planta transformation of Arabidopsis thaliana. Genetics 155:1875-1887
Bered F, Barbosa Neto JF, Rocha BM, da Carvalho FIF (2002) Genetic variability in wheat (Triticum aestivum L.) germplasm revealed by RAPD markers. Crop Breed Appl Biotechnol 2:499-505

Bregitzer P, Halbert SE, Lemaux PG (1998) Somaclonal variation in the progeny of transgenic barley. Theor Appl Genet 96:421425

Brunaud V, Balzergue S, Dubreucq B, Aubourg S, Samson F, Chauvin S, Bechtold N, Cruaud C, DeRose R, Pelletier G, Lepiniec L, Caboche M, Lecharny A (2002) T-DNA integration into the Arabidopsis genome depends on sequences of preinsertion sites. EMBO Rep 3:1152-1157

Castle LA, Errampalli D, Atherton TL, Frunzmann CH, Yoon ES, Mainke DW (1993) Genetic and molecular characterisation of embryonic mutants identified following seed transformation in Arabidopsis. Mol Gen Genet 241:504-514

Cervera M, Pina JA, Juarez J, Navarro L, Pena L (2000) A broad exploration of a transgenic population of citrus: stability of gene expression and phenotype. Theor Appl Genet 100:670 677

Clough SJ, Bent A (1998) Floral dip: a simplified method for Agrobacterium-mediated transformation of Arabidopsis thaliana. Plant J 16:735-743

Cullis CA (1990) DNA rearrangements in response to environmental stress. Adv Genet 28:73-97

Cullis CA, Cleary W (1986) DNA variationin flax tissue culture. Can J Genet Cytol 28:247-251

Cullis CA, Kolodynska K (1975) Variation in the isozymes of flax (Linum usitatissimum) genotrophs. Biochem Genet 13:687-697

Curtis IS, Nam HG (2000) Transgenic radish (Raphanus sativus L. Longipinnatus Bailey) by floral-dip method-plant development and surfactant are important in optimizing transformation efficiency. Transgenic Res 10:363-371

Dale PJ, McPartlan HC (1992) Field performance of transgenic potato plants compared with controls regenerated from tuber discs and shoot cuttings. Theor Appl Genet 84:585-591

Desfeux C, Clough SJ, Bent AF (2000) Female reproductive tissues are the primary target of Agrobacterium-mediated transformation by the Arabidopsis floral-dip Method. Plant Physiol 123:895-904

Dolezel J, Novak FJ (1984) Effect of plant tissue culture media on the frequency of somatic mutations in Tradescantia stamen hairs. Z Pflanzenphysiol 114:51-58

Etienne H, Bertrand B (2003) Somaclonal variation in Coffea arabica: effects of genotype and embryogenic cell suspension age on frequency and phenotype of variants. Tree Physiol 23:419-426

Gaj MD, Maluszynski M (1987) Genetic variation in callus culture of Arabidopsis thaliana (L.) Heynh. Arabidopsis Inf Serv 23:18

Gelvin SB (2000) Agrobacterium and plant genes involved in TDNA transfer and integration. Plant Mol Biol 51:223-256

Jong-Seong J, Sichul L, Ki-Hong J, Sung-Hoon J, Dong-Hoon J, Jinwon L, Chanhong K, Seonghoe J, Shinyoung L, Kiyoung Y, Jongmin N, Kyungsook A, Min-Jung H, Ryo-Jin S, Hyun-Sook C, Jung-Hwa Y, Jung-Hwan C, Se-Yu C, Sang-Su C, Shi-In K, Gynheung A (2000) T-DNA insertional mutagenesis for functional genomics in rice. Plant J 22:561-570

Karp A (1991) On the current understanding of somaclonal variation. Oxf Surv Plant Mol Cell Biol 7:1-58

Kimura M, Crow JF (1964) The number of alleles that can be maintained in a finite population. Genetics 49:725-738

Koncz C, Nèmeth K, Rèdei GP, Schell J (1992) T-DNA insertional mutagenesis in Arabidopsis. Plant Mol Biol 20:963-976

Labra M, Savini C, Bracale M, Pelucchi N, Colombo L, Bardini M, Sala F (2001) Genomic changes in transgenic rice (Oryza sativa L.) plants produced by infecting calli with Agrobacterium tumefaciens. Plant Cell Rep 20:325-330

Larkin PJ, Scowcroft WR (1981) Somaclonal variation: a novel source of variability from cell cultures for plant improvement. Theor Appl Genet 60:197-214 
Lawrence RJ, Pikaard CS (2003) Transgene-induced RNA interference: a strategy for overcoming gene redundancy in polyploids to generate loss-of-function mutations. Plant J 36:114-121

Márton L, Hrounda M, Pécsváradi A, Czakó M (1994) T-DNAinsert-independent mutations induced in transformed plant cells during Agrobacterium co-cultivation. Transgenic Res 3:317325

Miyashita NT, Kawabe A, Innan H (1999) DNA variation in the wild plant Arabidopsis thaliana revealed by amplified fragment length polymorphism analysis. Genetics 152:1723-1731

Murashige T, Skoog F (1962) A revised medium for rapid growth and bioassays with tobacco tissue cultures. Physiol Plant 15:473-497

Nei M (1987) Molecular evolutionary genetics. Columbia University Press, New York

Palilov AI, Khotyleva LV, Savchenko AP, Korpusenko LI, Anokhina TA, Polkanova TP, Danilov AS (1981) Polymorphism of plants in degree of cross pollination. Its biological importance, genetic basis and practical use. Nauka i tekhnika, Minsk

Phillips RL, Kaeppler SM, Olhoft P (1994) Genetic instability of plant tissue cultures: breakdown of normal controls. Proc Natl Acad Sci USA 91:5222-5226

Polanco C, Ruiz ML (2002) AFLP analysis of somaclonal variation in Arabidopsis thaliana regenerated plants. Plant Sci 162:817824

Pooran C, Singh SP (2003) Genetic diversity maintenance of cross pollinated germplasm. Prog Agric 3:1-7

Pradeep T, Sumalini K (2003) Impact of mating systems on genetic variability in segregating generations of Asiatic cotton (Gossypium sp.). Indian J Genet Plant Breed 63:143-147

Sachs ES, Benedict JH, Stelly DM, Taylor JF, Altman DW, Berberich SA, Davis SK (1998) Expression and segregation of genes encoding cryIA insecticidal proteins in cotton. Crop Sci 38:1-11

Sala F, Arencibia A, Castiglione S, Yifan H, Labra M, Savini C, Bracale M, Pelucchi N (2000) Somaclonal variation in transgenic plants. Acta Hortic 530:411-419

Sebastiani L. Lenzi A, Pugliesi C, Fambrini M (1994) Somaclonal variation for resistance to Verticillum dahliae in potato (Solanum tuberosum L.) plants regenerated from callus. Euphytica 80:5-11
Shannon CE, Weaver W (1949) The mathematical theory of communication. University of Illinois Press, Urbana

Sneath PHA, Sokal RR (1973) Numerical taxonomy. Freeman, San Francisco

Soniya EV, Banerjee NS, Das MR (2001) Genetic analysis of somaclonal variation among callus-derived plants of tomato. Curr Sci 80:1213-1215

Szabados L, Kovacs I, Oberschall A, Ábrahám E, Kerekes I, Zsigmond L, Nagy R, Alvarado M, Krasovskaja I, Gál M, Berente A, Rédei GP, Ben Haim A, Koncz C (2002) Distribution of 1000 sequenced T-DNA tags in the Arabidopsis genome. Plant J 32:233-242

Tague BW (2001) Germ-line transformation of Arabidopsis lasiocarpa. Transgenic Res 10:259-267

Thomas CM, Jones DA, English JJ, Carroll BJ, Bennetzen JL, Harrison K, Burbidge A, Bishop GJ, Jones JD (1994) Analysis of the chromosomal distribution of transposon-carrying $\mathrm{T}$ DNAs in tomato using the inverse polymerase chain reaction. Mol Gen Genet 242:573-585

Touraev A, Stoger E, Voronin V, Heberle-Bors E (1997) Plant male germ line transformation. Plant J 12:949-956

Trieu AT, Burleigh SH, Kardailsky IV, Maldonado-Mendoza IE, Versaw WK, Blaylock LA, Shin H, Chiou TJ, Katagi $\mathrm{H}$, Dewbre GR, Weigel D, Harrison MJ (2000) Transformation of Medicago truncatula via infiltration of seedlings or flowering plants with Agrobacterium. Plant J 22:531-541

Wang G, Castiglione S, Chen Y, Li L, Han Y, Tian Y, Gabriel DW, Han Y, Mang K, Sala F (1996) Poplar (Populus nigra L.) plants transformed with a Bacillus thuringiensis toxin gene: insecticidal activity and genomic analysis. Transgenic Res 5:289-301

Wu K, Jones R, Danneberger L, Scolnick PA (1994) Detection of microsatellite polymorphisms without cloning. Nucleic Acids Res 22:3257-3258

Ye GN, Stone D, Pang SZ, Creely W, Gonzalez K, Hin-chee M (1999) Arabidopsis ovule is the target for Agrobacterium in planta vacuum infiltration transformation. Plant J 19:249-257

Zupan J, Muth TR, Draper O, Zambrysky P (2000) Thee transfer of DNA from Agrobacterium tumefaciens into plants: a feast of fundamental insights. Plant J 23:11-28 